Research Article

\title{
Phenomenon and Critical Conditions of Chamber Soil Sliming during EPB Shield Tunneling in Water-Rich Weathered Diorite: Case Study of Jinan Metro, China
}

\author{
Lu Wang, ${ }^{1,2}$ Wei Zhu $\left(\mathbb{D},{ }^{3}\right.$ Yongjin Qian, ${ }^{1,2}$ Chao Xu, ${ }^{1,2}$ Jiannan Hu, ${ }^{1,2}$ and Huitang Xing ${ }^{4}$ \\ ${ }^{1}$ Key Laboratory of Geomechanics and Embankment Engineering of Ministry of Education, Hohai University, Nanjing 210098, \\ China \\ ${ }^{2}$ School of Civil and Transportation Engineering, Hohai University, Nanjing 210098, China \\ ${ }^{3}$ School of Environment, Hohai University, Nanjing 210098, China \\ ${ }^{4}$ Jinan Rail Transit Group Co., Ltd., Jinan 250000, China \\ Correspondence should be addressed to Wei Zhu; zhuweiteam.hhu@gmail.com
}

Received 3 January 2020; Revised 26 May 2020; Accepted 24 June 2020; Published 14 July 2020

Academic Editor: Chunshun Zhang

Copyright (c) $2020 \mathrm{Lu}$ Wang et al. This is an open access article distributed under the Creative Commons Attribution License, which permits unrestricted use, distribution, and reproduction in any medium, provided the original work is properly cited.

\begin{abstract}
The sliming problem of chamber soil is caused by excessive groundwater seeping into the pressure chamber when an Earth pressure balance shield tunnels through a water-rich weathered rock stratum under semiopen under-pressure mode. As a solution to this problem, a calculation model was established based on field measurements of the discharged soil properties, the seepage water volume, and the seepage path in Jinan Metro, China. Chamber soil sliming is a phenomenon in which chamber soil is in a thin mud state, with no pressure balance in the pressure chamber of the EPB shield and an excessive water content of the chamber soil owing to the continuous seepage of groundwater into the chamber. The chamber pressure is relatively low, which is different from the phenomenon of spewing when the chamber pressure is relatively high. A large amount of water seepage from the stratum around the tunnel excavation surface and shield to the chamber is a significant factor leading to chamber soil sliming during the construction process. It was considered that when the moisture content of the chamber soil, $w$, is $2 w_{L} \leq w \leq 3 w_{L}$, slight chamber soil sliming may occur, whereas when $w \geq 3 w_{L}$, serious chamber soil sliming may occur. Moreover, some measures to prevent and control the occurrence of chamber soil sliming were discussed. Controlling the advancing time and the permeability coefficient of chamber soil during construction is the most effective measure to avoid the phenomenon of soil sliming.
\end{abstract}

\section{Introduction}

In recent years, an increasing number of tunnels passing through water-rich rock zones have become necessary. There are abundant case studies and summaries on mountain tunnels based on experience. Most mountain tunnels have adopted a mining method, and, during the process of construction, water inrush and mud outburst accidents easily occur [1-3]. However, owing to a limitation of an urban environment, metro tunnels are usually constructed through a shield method, which achieves a high level of safety. However, when the geological conditions in front of the excavation face are unclear, it will lead to an instability and water gushing of the excavation face $[4,5]$. At present, there is a lack of case studies and engineering experience on subway tunnels passing through the rock strata in a city.

During construction, an Earth pressure balance (EPB) shield is often used under a semiopen under-pressure mode [6-8]; that is, the pressure chamber is not filled with excavated soil and the pressure of the chamber is not applied to balance the Earth pressure and water pressure at the excavation surface. The principle of EPB shield to maintain the stability of excavation surface is to use the pressure of chamber soil to balance the Earth pressure and water pressure on the excavation surface. At this time, the pressure chamber is full of excavated soil. In areas where the stratum can stand alone steadily and the surface settlement is not very sensitive, in order to pursue a faster construction speed, 
the construction with a nonfull chamber is generally adopted, which will not affect the stability of the excavation surface; at the same time, a faster construction speed can be obtained under a smaller thrust and torque, and the requirements for the chamber soil conditioning are relatively simple. Therefore, the construction of semiopen underpressure mode is common in projects. This type of situation often occurs in a soft rock stratum, which can stand alone and remain stable, as well as in medium-coarse sand and a sandy-pebble stratum. Under this situation, it is difficult to form a plastic flow in the chamber soil. The soil in the plastic flow state is paste-like, the permeability coefficient of the soil is less than $10^{-5} \mathrm{~m} / \mathrm{s}$, the slump is $150-200 \mathrm{~mm}$, and the high compressibility usually requires a volume compression rate of at least $2 \%$ and low shear strength [9]. Owing to the difficulty in forming a plastic flow of soil in a pressure chamber, an EPB shield is prone to spewing [10-13], blocking, and cake formation [14-19], as well as other phenomena during the construction of such strata. The EPB shield originates from the construction of a soft clay stratum, which easily forms a plastic flow after being disturbed in the pressure chamber. The soil in the pressure chamber not only balances the Earth and water pressure on the excavation surface but also discharges the soil smoothly under the control of a screw conveyor. When the pressure chamber is not filled with excavated soil and the pressure does not reach the earth-water pressure on the excavation surface, the tunneling state of the shield is between EPB mode and open mode, which can be called a semiopen-mode EPB shield construction.

Although a semiopen-mode EPB shield construction can solve the problem of blocking in a complex stratum, there is no balanced relationship among the chamber pressure, Earth pressure, and water pressure of the stratum. Therefore, in addition to the potential instability of the excavation surface and the risk of surface deformation, the discharging system and grouting system will also be affected. In a permeable stratum, if the groundwater pressure is greater than the chamber pressure, a large amount of groundwater will seep into the pressure chamber and affect the soil discharge. Meanwhile, if the conventional grouting pressure behind the segments is adopted, grout leakage will occur, in which the grout behind the segments flows to the pressure chamber [20].

Some scholars have studied the construction performance and suitable driving mode of an EPB shield in different strata. According to the relationship between the pressure of the pressure chamber and the underground earth-water pressure on the excavation face, the driving mode of the EPB shield can be divided into four categories: open mode, semiopen mode, EPB mode, and over-pressure mode. James studied the construction parameters and cutter wear of an EPB shield and slurry shield when driving in the composite stratum of soil and weathered igneous rock [21]. This research shows that when the proportion of rock on the excavation section is more than $15 \%$, the average driving speed of the EPB shield is significantly reduced. When the proportion of rock is more than $95 \%$, an open driving mode is appropriate. In Hong Kong and Singapore, some EPB shield tunnels under the conditions of weathered igneous rock and a soil composite excavation face have adopted a semiopen mode to reduce the wear and torque under full cabin construction. In semiopen mode (also known as semiEPB mode), there is no soil in the upper half of the pressure tank, and the support pressure is provided by compressed air [22]. When the air pressure of the upper part is less than the Earth and water pressure of the excavation face, it is called semiopen under-pressure mode. To date, there have been few case studies on the construction of an EPB shield with a semiopen under-pressure in the literature.

At present, there is lack of systematic studies and engineering experience in the construction of an EPB shield in water-rich weathered rock using semiopen mode. Most of the shield tunnels of the R2 line of Jinan Metro are located in water-rich weathered diorite stratum. The groundwater is rich, and the weathering degree of the rock stratum is uneven. During the EPB shield tunneling, many semiopen under-pressure modes occurred, as did the typical problem of a chamber soil sliming. Regarding the occurrence of this problem and the formulation of proper solutions, in this study, the parameters of the construction and discharged soil on the construction site and the seepage flow in the chamber are measured. A theoretical analysis was conducted, and the principle and control measures of chamber soil sliming are discussed herein.

\section{Project Overview and Problems}

2.1. Project Overview. Jinan is the capital of Shandong Province in China, with a total area of $10,244 \mathrm{~km}^{2}$ and a permanent population of 7.5 million as of 2018. Jinan is rich in springs, which has created challenges for the construction of the metro lines. The layout of the Jinan Metro lines and the distribution of the springs are shown in Figure 1. The first phase of Jinan Metro line R2 is an east-west urban line connecting the key areas of Jinan, such as the Lashan area, the core area of the western new city, the old urban area, and the high-tech zone. It is a backbone rail transit line aiming to relieve the east-west traffic pressure and support the spatial expansion of the strip city. Phase I of the R2 line starts from Wangfuzhuang station in the west and ends at Pengjiazhuang station in the east, with a total length of approximately $36.302 \mathrm{~km}$, including a $34.502 \mathrm{~km}$ underground line, a $1.489 \mathrm{~km}$ elevated line, and a $0.311 \mathrm{~km}$ open section. The tunnel is expected to be officially opened to traffic by the end of 2020. The interval tunnel is being constructed using a four-spoke panel composite-type EPB shield with a cutter head opening rate of $40 \%$. As shown in Figure 2, the cutter head excavation diameter is $6.68 \mathrm{~m}$, and the device is equipped with 37 disc cutters and 48 scrapers. The basic parameters of the shield machine are listed in Table 1 . The buried depth of the tunnel is approximately 4.9-49.7 m, and the geology along the tunnel is complex, including completely weathered diorite, strongly weathered diorite, and moderately weathered diorite, limestone, silty clay, gravelly soil, and sandy-pebble stratum. Among these strata, the tunnel passes through the weathered diorite for the longest 


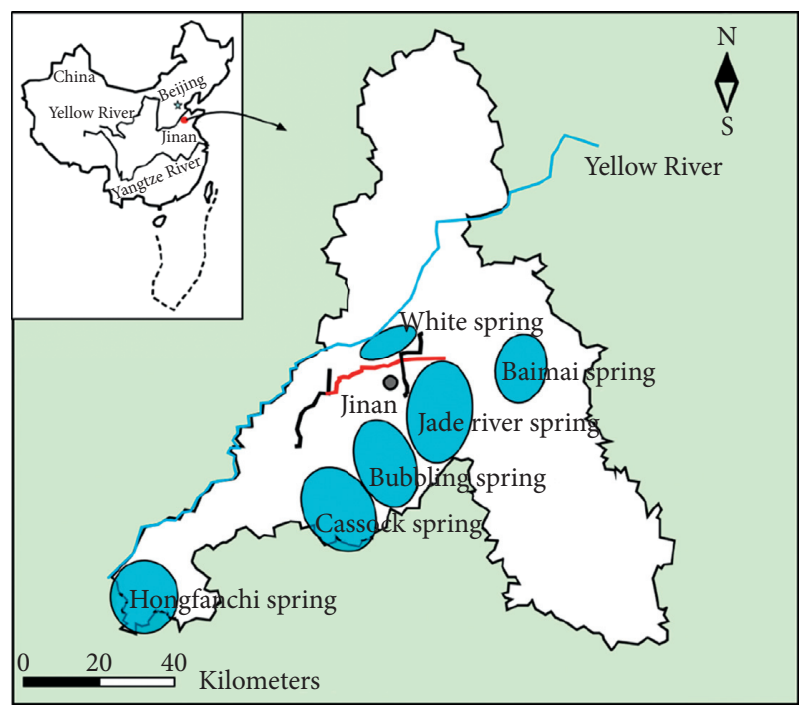

Spring group

R2 line

- Other metro lines

FIgURE 1: Location and general layout of Jinan Metro lines and distribution of the main spring groups.

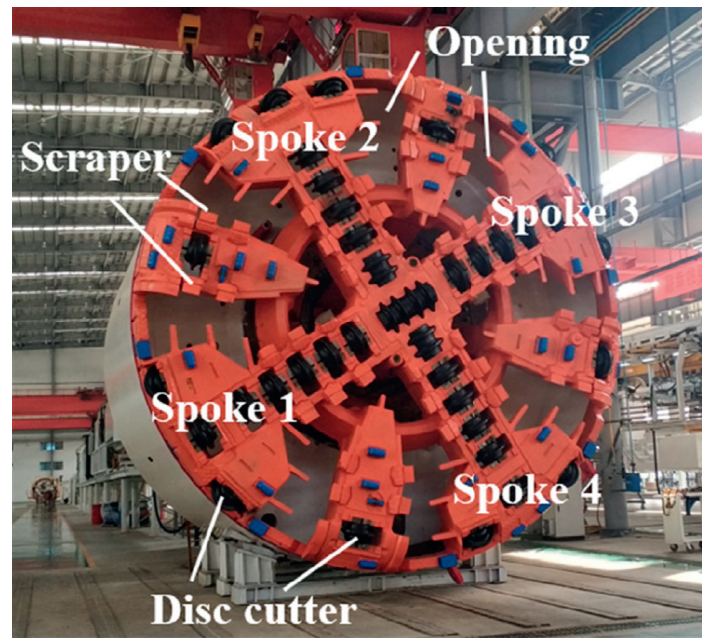

Figure 2: Cutter wheel of EPB shield used in Jinan Metro line R2.

distance, which is more than $30 \%$ of the total length of the underground line, that is, approximately $11 \mathrm{~km}$.

The research object is a section of the R2 line of Jinan Metro. The interval tunnel is $1.003 \mathrm{~km}$ long, with a depth of 9.7-17.7 $\mathrm{m}$, and the groundwater buried depth is approximately $2 \mathrm{~m}$. The main strata traversed in the interval are completely weathered diorite, strongly weathered diorite, and moderately weathered diorite. The strata profiles are shown in Figure 3. The completely weathered diorite has a high degree of weathering, and the strongly weathered diorite has a good self-stability before excavation. After being disturbed by the cutter head, the strongly weathered diorite forms soil particles similar to medium-coarse sand with a large permeability coefficient and little cohesion. The
TABle 1: Basic parameters of shield machine.

\begin{tabular}{lcc}
\hline Name & Parameter & Unit \\
\hline Model & CTE6650H-0945 & \\
Project name & Jinan Metro line & \\
& R2 & \\
Segment (OD/ID, width) & $\Phi$ 6,400/5,800, & $\mathrm{mm}$ \\
Excavation diameter & $\sim 1,200$ & \\
Cutter speed & $\Phi 6,680$ & $\mathrm{~mm}$ \\
Maximum excavating speed & $0 \sim 3.15$ & $\mathrm{rpm}$ \\
Maximum thrust & $\approx 80$ & $\mathrm{~mm} /$ \\
Total length of shield & 4,255 & $\mathrm{~min}$ \\
Total length of main machine & $\approx 85$ & $\mathrm{~T}$ \\
(excluding cutter head) & 8,389 & $\mathrm{~m}$ \\
Maximum design pressure & 5 & $\mathrm{~mm}$ \\
Cutter head size (diameter; length) & $\Phi 6,680,1,645$ & $\mathrm{bar}$ \\
Cutter head opening rate & 40 & $\%$ \\
\hline
\end{tabular}

$\mathrm{OD}=$ outer diameter; $\mathrm{ID}=$ internal diameter.

moderately weathered diorite has high strength and good self-stability. The specific geological parameters are listed in Table 2.

2.2. Engineering Geology. The geomorphic unit of the project tunnel is piedmont alluvial plain. The terrain along the tunnel line is generally gentle, and the ground elevation is between 25.97 and $26.79 \mathrm{~m}$, with a maximum height difference of approximately $0.82 \mathrm{~m}$. The strata involved in the project are mainly Yanshanian intrusive gabbro, diorite, and a Cenozoic quaternary system.

Diorite with different degrees of weathering is widely distributed along the project. Diorite contains mainly plagioclase, quartz, amphibole, epidotes, calcite, pyrite, and chloride [23]. The face of the completely weathered diorite is grayish-yellow to grayish-green in color, the original rock structure has been destroyed, and the core is mostly of a sand type, which is fragile when handled by hand. The face of the strongly weathered diorite is grayish-green to grayish-yellow in color, and the original rock has a clear, medium-coarse grain structure, with the development of joint fissures. In addition, the core is mostly fragmentary, with a short column and occasionally a long column, and is fragile from hammering with a core recovery rate of $75 \%-85 \%$. The moderately weathered diorite is grayish-green with a medium-coarse grain structure, is of a block type, and has slightly developed joint fissures. A calcite dyke can be seen in the moderately weathered diorite. The core is mostly columnar with a length of $10-25 \mathrm{~cm}$ and the core recovery rate is $80 \%-90 \%$. Meanwhile, there are many completely to strongly weathered soft intercalations in some parts of moderately weathered diorite.

The completely weathered and strongly weathered diorite softens when encountering water, and its strength decreases after saturation. Some sections of the tunnel are located in structural fracture zones and rock layers with different degrees of weathering. Under the influence of adverse factors such as groundwater action and construction 


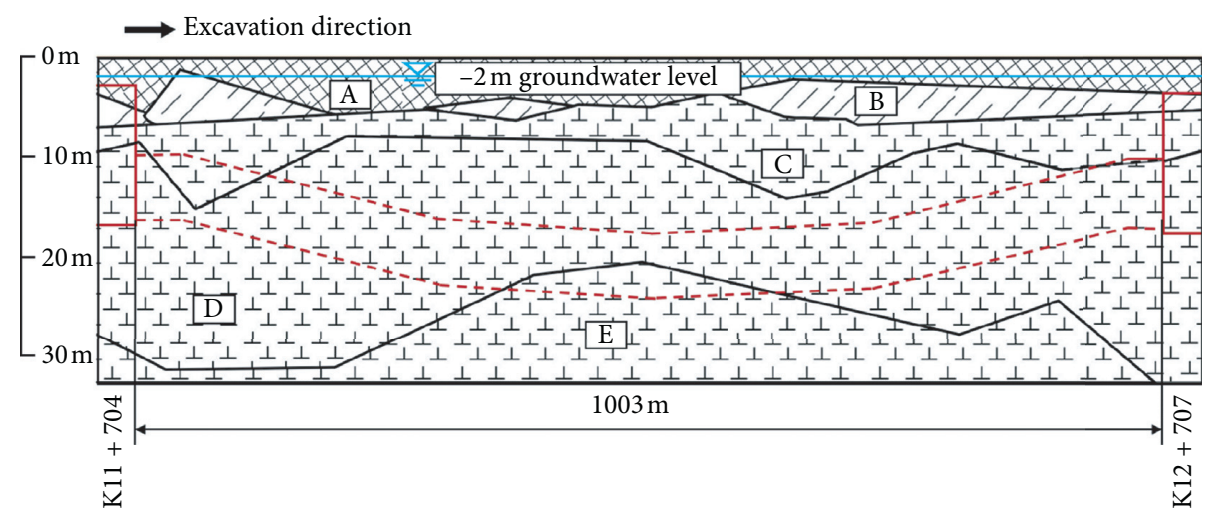

Figure 3: Geological section of a section of Jinan Metro line R2. A, backfill soil; B, silty clay; C, completely weathered diorite; D, sandy strongly weathered diorite; $\mathrm{E}$, moderately weathered diorite.

TABLE 2: Geological parameters of the interval tunnel.

\begin{tabular}{|c|c|c|c|c|c|c|c|}
\hline Soil & $\rho\left(\mathrm{g} / \mathrm{cm}^{3}\right)$ & $w(\%)$ & $w_{L}(\%)$ & $w_{P}(\%)$ & Dry & $\sigma_{c}$ saturated $(\mathrm{MPa})$ & $k(\mathrm{~m} / \mathrm{s})$ \\
\hline Backfill soil & 1.78 & 22.1 & - & - & - & - & - \\
\hline Silty clay & 1.93 & 23.5 & 34.4 & 21.3 & - & - & $3.25 \times 10^{-8}$ \\
\hline Completely weathered diorite & 1.96 & 20.9 & 27.4 & 18.8 & - & - & $3.4 \times 10^{-5}$ \\
\hline Sandy strongly weathered diorite & 2.15 & - & - & - & 17.5 & 11.9 & $2.3 \times 10^{-5}$ \\
\hline Moderately weathered diorite & 2.31 & - & - & - & 58.3 & 48.6 & - \\
\hline
\end{tabular}

$\rho=$ natural density; $w=$ natural moisture content; $w_{L}=$ liquid limit; $w_{P}=$ plastic limit; $\sigma_{c}=$ uniaxial compressive strength; $k=$ hydraulic conductivity.

disturbances, adverse engineering phenomena such as seepage and a piping effect are easy to occur during the process of foundation pit construction, and accidents such as a water inrush, a mud outburst, and collapse easily occur during the construction of a connecting passage when the mining method is used [24], which are also challenges to a shield construction method.

\subsection{Chamber Soil Sliming Phenomenon}

2.3.1. Section State. According to the construction of the R2 line of Jinan Metro, when the EPB shield tunnel passes through a full section of strongly weathered diorite or the upper section is strongly weathered diorite and the lower section is moderately weathered diorite, owing to the good self-stability of the tunnel excavation face and the insensitivity of the surface settlement, a semiopen under-pressure driving mode is adopted. When passing through the weathered diorite stratum, the stratum permeability coefficient is approximately $10^{-5} \mathrm{~m} / \mathrm{s}$. The soil is in the form of debris after the cutter head excavation, without cohesion, and soil-water separation occurs.

The weathered rock is cut by the disc cutter to form coarse and fine rock powder, whereas the rich fissure groundwater seeps into the chamber and mixes with the rock powder to form a mud-like soil, which is discharged using a screw conveyor. However, because the discharged soil is almost in a thin mud state, the soil in the joint part of the screw conveyor and the belt conveyor leaks, and the cleaning of a large amount of thin mud-like soil at the bottom of the tunnel significantly reduces the construction efficiency. This phenomenon can be called chamber soil sliming. The essential difference between soil sliming and spewing is whether the pressure in the pressure tank is maintained or not. When the spew occurs, the chamber is in a pressuremaintaining state, and the higher chamber pressure acts on the soil and pore water, but when the chamber soil lacks the necessary plastic flow state, the pore water pressure in the soil cannot be effectively dissipated during the process of discharge by the screw conveyor. After the soil is disturbed, the water in the soil pore forms a concentrated seepage channel and moves outward together with the soil particles. The mixture of soil and water originally discharged at the same speed generates a relative movement. When the seepage of water with a high-water pressure flows to the outlet, there is a large pressure difference with the external atmospheric pressure, resulting in a rapid outflow of water in the soil and a driving of the transported soil, causing spewing $[10,11,25,26]$. Therefore, spewing occurs under a full chamber state, the pressure in the chamber is relatively large, and the chamber soil is a mixture of soil and water with high fluidity. However, when soil sliming occurs, there is no pressure-maintaining in the chamber, the volume of soil in the chamber is less, and the pressure in the chamber is lower. Generally, the chamber pressure is slightly higher than the gravity pressure of the chamber soil, and the underground water pressure is greater than the chamber pressure. A large amount of underground water infiltrates into the chamber, resulting in the mud-like soil. Meanwhile, the two conditions also have different impacts on the construction. The spewing may cause the instability of the excavation surface, the loss of groundwater, and the surface settlement. It can be alleviated by injecting bentonite slurry and other soil 
conditioning additives into the chamber. However, soil sliming usually occurs in the stratum that can stand on its own, so it basically does not affect the stability of the excavation surface. Due to the small amount of soil in the chamber and the high moisture content of the chamber soil, the soil conditioning additives will be diluted by water quickly after being added to the chamber, making it difficult to control and solve the problem of chamber soil sliming in a timely manner.

2.3.2. Construction Parameters. The self-stability of strongly and moderately weathered diorite is high. To improve the construction speed, the construction workers adopted a semiopen under-pressure tunneling mode. The strata traversed by the EPB shield in the first 330 rings on the left line of the tunnel in this area were mainly full-section highly weathered diorite. Under semiopen under-pressure tunneling mode, the average excavating speed of each ring was $20-30 \mathrm{~mm} / \mathrm{min}$, with the maximum reaching $43 \mathrm{~mm} / \mathrm{min}$; the excavation time of each ring was approximately $0.8 \mathrm{~h}$ and the average torque of each ring was approximately $3,600 \mathrm{kN}$ $\mathrm{m}$; and the chamber soil could be normally discharged. When driving to the 330th ring, moderately weathered diorite invaded the lower part of the excavation section. When driving to the 340-350th rings, the speed was rapidly reduced to $2 \mathrm{~mm} / \mathrm{min}$. Meanwhile, as the strength of the stratum on the excavation surface increased, the penetration degree of the cutter decreased, and the torque was approximately $2,700 \mathrm{kN}-\mathrm{m}$, as shown in Figure 4 . According to the construction parameters of the left line shield machine in rings 300-350, the volume of the chamber soil accounted for $1 / 3$ to $1 / 2$ of the volume of the pressure chamber, and the top chamber pressure was 0 bar. According to the buried depth of the tunnel, the water pressure at the top of the excavation face was approximately 1.5 bar, and hence no air pressure was applied at the top to balance the soil and water pressure at the excavation face. The pressure in the middle and bottom of the pressure chamber is shown in Figure 5 when the EPB shield passed the 300-350th rings. Because the excavation face has a self-stability, the lateral Earth pressure of the excavation face acting on the shield machine was not considered. As can be seen from Figure 5, the groundwater pressures in the middle and bottom of the excavation face were approximately 1.76 and 2.1 bar, respectively. The chamber pressure in the construction process was significantly lower than the underground water pressure in the section. Under the action of the pressure difference between the groundwater pressure and the chamber pressure, as well as a slow speed, continuous seepage of the groundwater into the pressure chamber occurred. Meanwhile, a composite stratum with an uneven strength may cause damage to the cutter; to further understand the condition of the excavation face and cutter wear, the EPB shield can be stopped and the chamber opened for inspection.

2.3.3. Moisture Content of Discharged Soil. To clarify the degree of chamber soil sliming of Jinan Metro line R2 and provide verification data for the subsequent calculation, moisture content tests were conducted on the soil samples taken from the discharged soil pit at the construction site and the outlet of the screw conveyor, resulting in a moisture content of approximately $55 \%-60 \%$. In addition, the plastic limit of the discharged soil, $w_{P}$, was $16.9 \%$, and the liquid limit, $w_{L}$, was $21.5 \%$. Therefore, the actual moisture content of the discharged soil reached 2.6-2.8 $w_{L}$. The discharged soil showed poor workability and occupied the site and, under a state of water and soil separation, was difficult to transport out. The discharged soil at the construction site is shown in Figure 6.

\section{Measurement Method and Calculation Model of Water Seepage}

3.1. Measured Section and Method. To solve the problem regarding the amount of groundwater that will permeate into the pressure chamber during the construction of each ring when the chamber is not full and under-pressure, a field seepage test was conducted. The seepage amount of the tunnel in this area was measured at the open section of the 350th ring of the left line. The measured cross section stratum comprised strongly weathered diorite in the upper part and moderately weathered diorite in the lower part, with good self-stability of the excavation surface and rich fissure water, as shown in Figure 7. The buried depth of this section was approximately $16.2 \mathrm{~m}$, the groundwater was $2 \mathrm{~m}$, and the permeability coefficient was approximately $10^{-5} \mathrm{~m} / \mathrm{s}$.

Owing to the high self-stability of the excavation surface, a method for opening the chamber under normal pressure was adopted in this project. After the soil in the chamber was discharged completely, the construction personnel could open the pressure chamber and enter the chamber for a removable cutter-changing operation. However, to safely and conveniently observe the change in the water level in the chamber, the height of the controlled chamber soil was located near the central cutter; that is, the height of the soil in the chamber was $1 / 2$ the height of the pressure chamber, and the soil was in a saturated state. Under a different water head, the continuous infiltration of groundwater will cause a rise in the water level of the chamber. The measurement personnel observed the source of water seepage in the man lock and recorded the difference in the water level in the chamber every hour. According to the difference in the water level, the water seepage from the stratum to the chamber could be obtained. Considering the relatively large permeability coefficient, a long measurement time, a large amount of water seepage, and the safety of the measured personnel, when the water level was close to the bottom plate of the man lock, the water pump was used to pump out the excess water in the chamber until the top of the chamber soil was exposed, and the rise of the water level was then recorded again. The above steps were repeated until the measurement time reached $4 \mathrm{~h}$.

3.2. Principle of the Seepage Calculation Model. Under a semiopen under-pressure condition, in addition to the seepage from the excavation surface into the chamber, a large amount of water seepage occurred in the gap between 


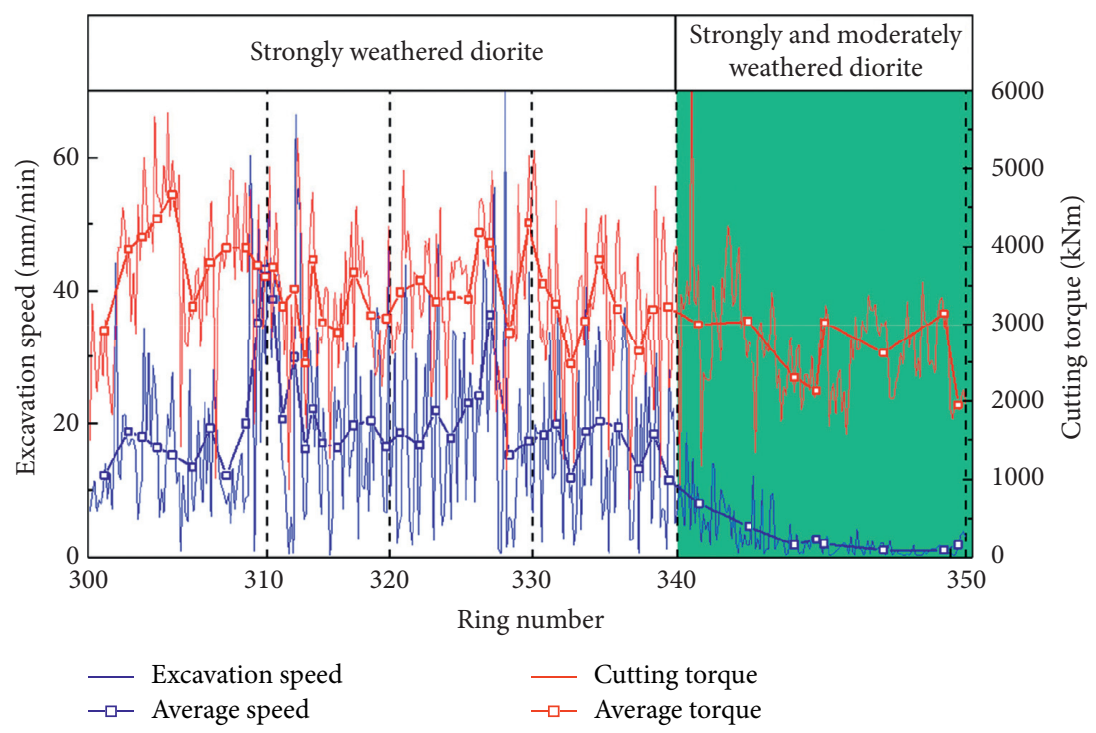

FIgURE 4: Monitoring results of excavation speed and cutting wheel torque at 300-350 rings.

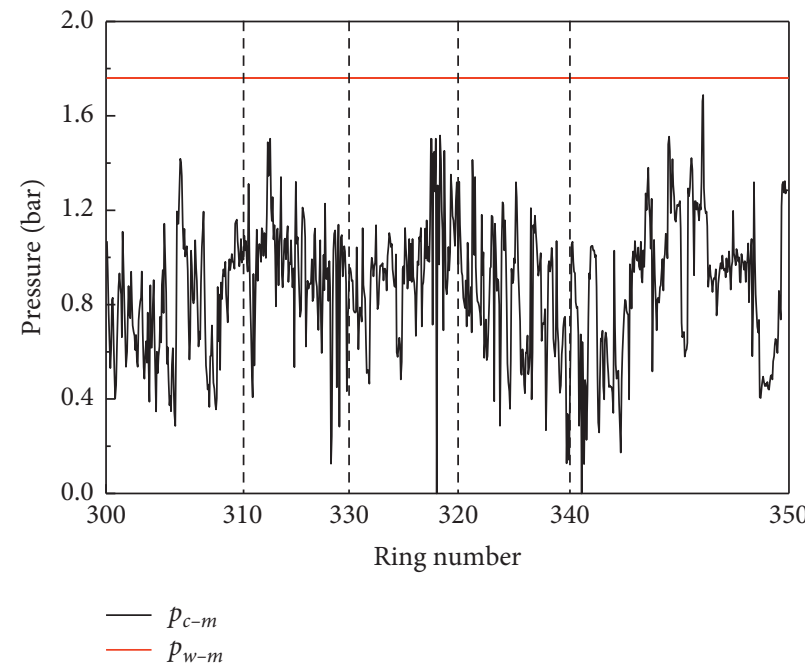

(a)

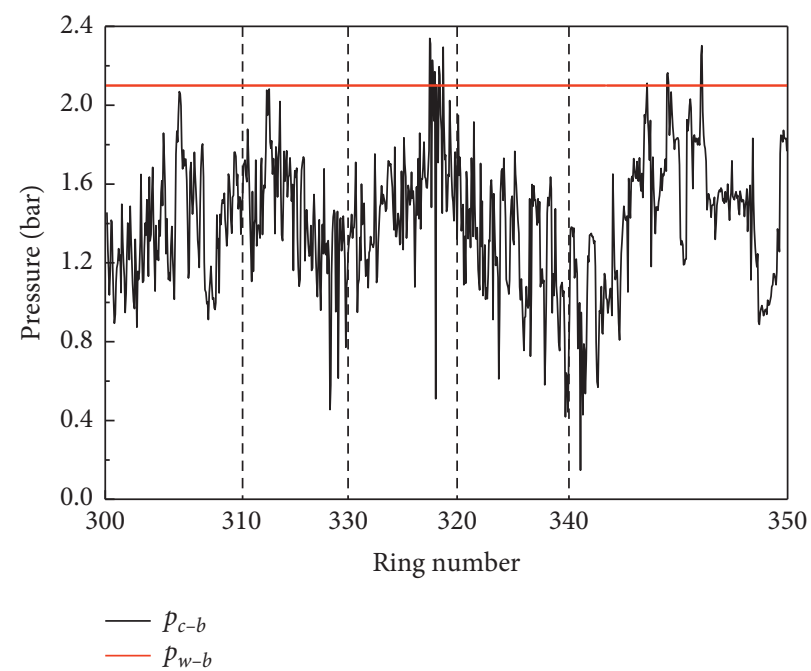

(b)

FiguRE 5: Chamber pressure of the shield and water pressure of excavation surface wheel at 300-350 rings. $p_{c-m}$ is the pressure in the middle of the pressure chamber, $p_{w-m}$ is the water pressure in the middle of the excavation surface, $p_{c-b}$ is the pressure at the bottom of the pressure chamber, and $p_{w-m}$ is the water pressure at the bottom of the excavation surface.

the shield shell and the surrounding rock. This is probably due to the existence of an overbreak in the relatively hard weathered rock; the tunneling diameter is slightly larger than the shield diameter, and thus a gap between the shield and stratum appears. Because the surrounding rock has good self-stability, a gap can occur from the cutter head to the tail of the shield. Around the tail of the shield, owing to the filling effect of grout behind the segment, the gap might disappear. During tunneling, in addition to synchronous grouting of the gap at the tail of the shield, secondary grouting was also conducted through the grouting holes on the segments, and thus it can be considered that there was no groundwater seepage around the segment rings after the shield tail $[27,28]$. When establishing the water seepage model, it was assumed that the chamber soil was saturated, and the excavation surface and surrounding rock of the shield were considered as the groundwater seepage surfaces. The groundwater head and permeability coefficient of the surrounding rock, as well as the water head in the chamber soil, were the boundary conditions of the seepage. The excavation speed of the tunnel affected the time of groundwater seepage into the chamber during the construction of each ring.

\section{Results}

4.1. Measured Water Seepage. According to the above measurement method, the volume of groundwater seepage into the chamber was calculated based on the change in the 


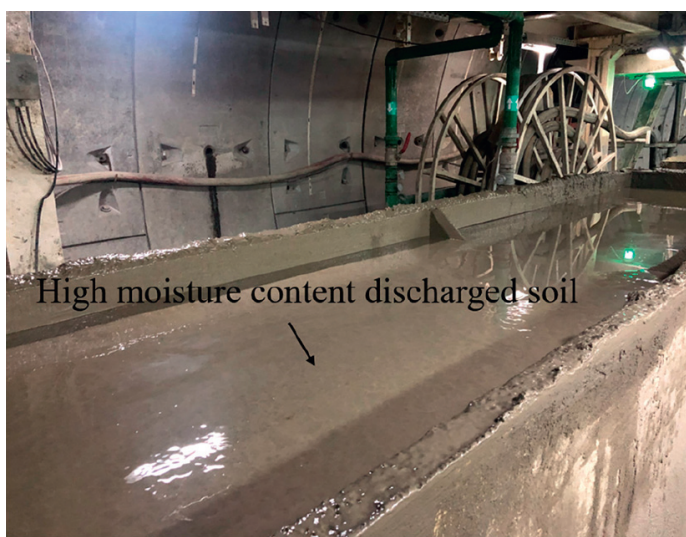

(a)

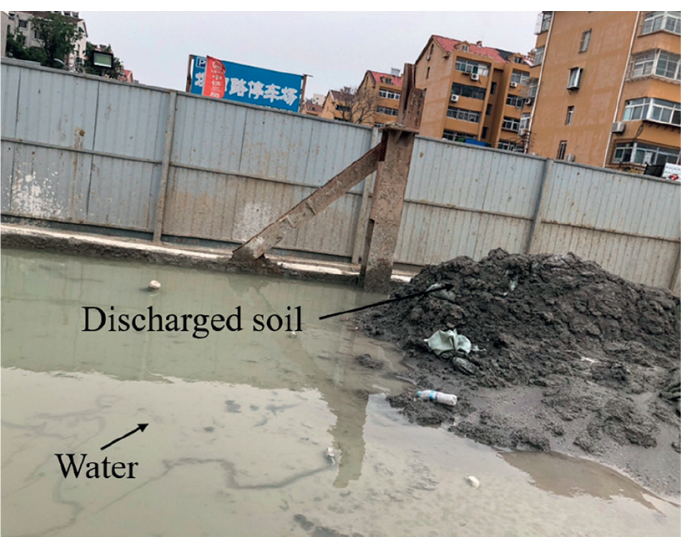

(b)

Figure 6: Discharged soil at the construction site.

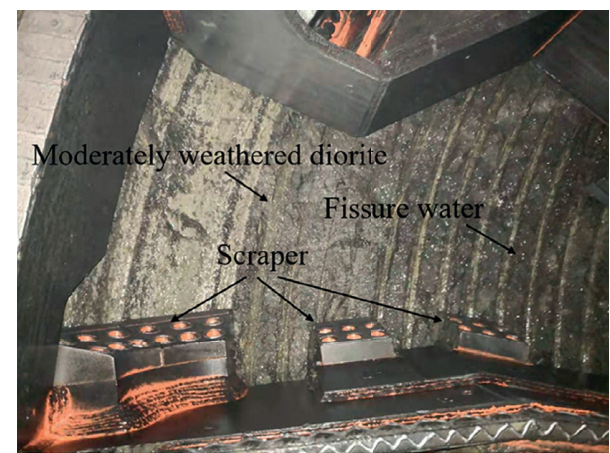

Figure 7: Excavation surface condition during field seepage measurement.

water level in the chamber within a certain time. The tunnel adopted synchronous grouting and secondary grouting behind the segments and applied a C-S grout to form a water stop hoop between the segment rings and the stratum every five rings. Thus, it can be considered that there was less water seepage in the chamber behind the shield tail. According to the observation in the man lock, the groundwater seepage into the chamber was mainly the fissure water of the tunnel excavation surface and the stratum around the shield, particularly the latter. The measured value of water seepage from the stratum to the chamber is shown in Figure 8. As shown here, after $0.5,3$, and $4 \mathrm{~h}$, volumes of $3.8,22.8$, and $30.4 \mathrm{~m}^{3}$ of groundwater seeped into the pressure chamber, respectively.

\subsection{Seepage Model and Calculation Results}

4.2.1. Calculation Model and Parameters. Based on Darcy's law and taking a certain section of the R2 line of the Jinan Metro as the prototype, a calculation model of the surrounding rock groundwater seepage into the chamber was established, a model diagram of which is shown in Figure 9. In the model, $H$ and $H_{w}$ are the tunnel and groundwater

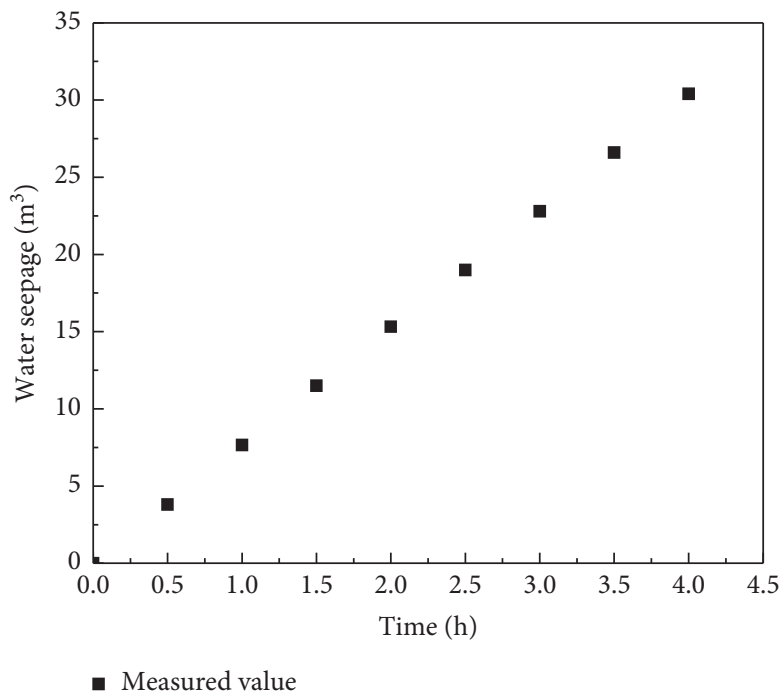

FIgURE 8: Measured value of water seepage.

depths, respectively; $h_{w}$ is the groundwater head at the top of the tunnel; $\alpha$ is the water head coefficient in the chamber, which refers to the ratio of the water head height in the chamber and the tunnel diameter; $\alpha D$ and $D$ are the water head height in the chamber and the tunnel diameter, respectively; and $L$ is the shield length. It can be seen from Figure 9 that the groundwater head at the bottom of the tunnel excavation face is $h_{w}+D$, whereas the water head at the bottom of the pressure chamber is $\alpha D$. There is a water head difference, $\Delta h$, between the bottom of the excavation face and the bottom of the pressure chamber, under which the groundwater will gradually seep into the pressure chamber. The model is suitable for the water-rich stratum with good self-stability and no obvious difference of permeability coefficient between the excavation face and the stratum along the direction of shield cylinder. The stratum used in the calculation model was weathered diorite, which was similar to medium-coarse sand with little cohesion 


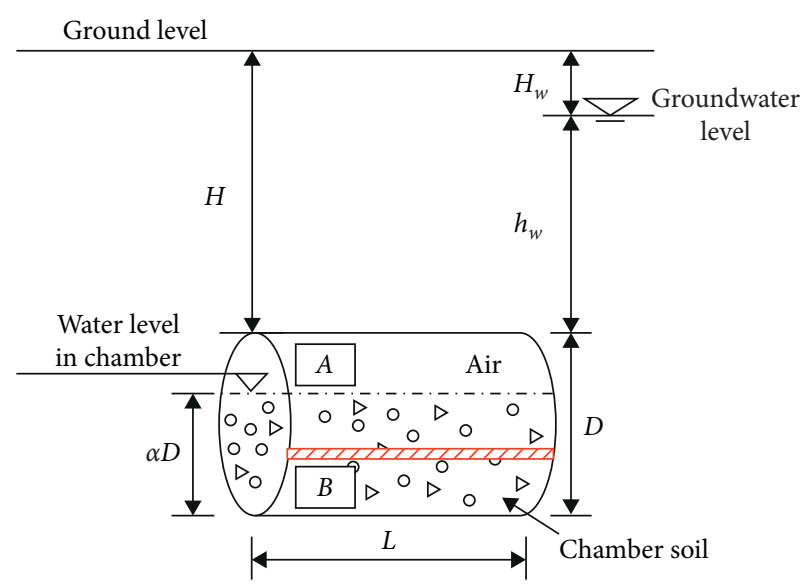

(a)

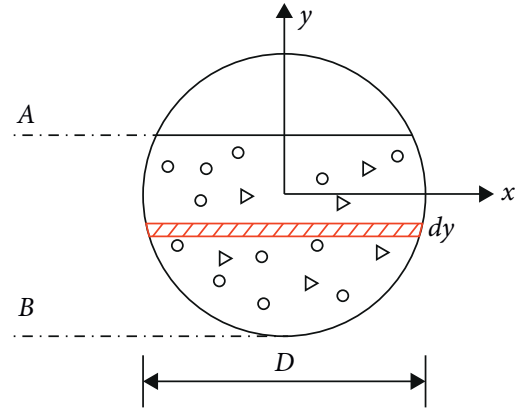

(b)

FIGURE 9: Schematic of the seepage model.

after excavation. The permeability coefficient of the stratum was approximately $10^{-5} \mathrm{~m} / \mathrm{s}$, and the buried depths of this tunnel section and the groundwater were 16.2 and $2 \mathrm{~m}$, respectively. The initial water content of the stratum was $20 \%$, the excavation diameter was $6.68 \mathrm{~m}$, the shield length was $8.389 \mathrm{~m}$, the excavation time was $4 \mathrm{~h} / \mathrm{ring}$, and the segment width was $1.2 \mathrm{~m}$. The chamber soil volume accounted for $1 / 2$ of the chamber volume, and the water level in the chamber was the same as the height of the chamber soil.

4.2.2. Calculation of Seepage from the Stratum around the Shield. During the excavation in semiopen mode, the water seepage around the shield was divided into parts A and B, as shown in Figure 9. There are differences in the hydraulic gradients between the part without chamber soil, part A, and that with chamber soil, part B, during the seepage process. The hydraulic gradient of part $A$ is 1 , whereas the hydraulic gradient of part B is related to the location of the selected calculation unit.

As shown in Figure 9, the length of the shield is $L$ and the water seepage from the stratum around the shield in part $\mathrm{A}$ is as follows:

$$
\begin{aligned}
i_{\mathrm{SA}} & =1, \\
Q_{\mathrm{SA}} & =k i_{\mathrm{SA}} A_{\mathrm{SA}} t .
\end{aligned}
$$

To simplify the calculation, the hydraulic gradient of the soil element in the middle of the chamber soil was obtained to calculate the water seepage from the stratum around the shield in part B, which is expressed as follows:

$$
\begin{aligned}
i_{\mathrm{SB}} & =\frac{h_{w}+(1-\alpha) d}{h_{w}+(1-\alpha / 2) d}, \\
Q_{\mathrm{SB}} & =k i_{\mathrm{SB}} A_{\mathrm{SB}} t,
\end{aligned}
$$

where $i$ is the hydraulic gradient, referring to the ratio of head loss along the seepage path to the length of the seepage path; $Q_{S}$ is the water seepage of the stratum around the shield for a certain period of time, $\mathrm{m}^{3} ; h_{w}$ is the groundwater head at the top of the tunnel, $m$; $\alpha$ is the coefficient of the water head in the chamber, referring to the ratio of the height of the water head in the pressure chamber to the diameter of the tunnel; $d$ is the tunnel diameter, $m ; k$ is the permeability coefficient of the stratum, $\mathrm{m} / \mathrm{s} ; A$ is the seepage area, $\mathrm{m}^{2}$; and $t$ is the seepage time, $h$.

4.2.3. Calculation of Seepage on the Excavation Surface. Under the condition of semiopen under-pressure driving mode, the water seepage on the excavation surface is also comprised of two parts.

The seepage volume of part A of the excavation surface is as follows:

$$
\begin{aligned}
i_{\mathrm{FA}} & =1, \\
Q_{\mathrm{FA}} & =k i_{\mathrm{FA}} A_{\mathrm{FA}} t .
\end{aligned}
$$

The center of the tunnel was taken as the origin of the coordinate axis, as shown in Figure 9. The calculation unit was selected and integrated along the height of the chamber soil, and the calculation formulas of the seepage volume of part B of the excavation surface were obtained as follows: 


$$
\begin{aligned}
& Q_{\mathrm{FB}}=2 k t \int_{-(d / 2)}^{(\alpha-(1 / 2)) d} \frac{h_{w}+(1-\alpha) d}{h_{w}+(d / 2)-y} \sqrt{\frac{d^{2}}{4}-y^{2}} \mathrm{~d} y, \\
& \quad-\sqrt{h_{w}^{2}+h_{w} d} \arcsin \left[\frac{2 h_{w}(\alpha-(1 / 2))+d(\alpha-1)}{\left|(\alpha-1) d-h_{w}\right|}\right] \\
& Q_{\mathrm{FB}}=2 k t\left[h_{w}+(1-\alpha) d\right]\left\{\begin{array}{r}
+\left(h_{w}+\frac{d}{2}\right) \arcsin (2 \alpha-1)-d \sqrt{\alpha(1-\alpha)}+1.57\left(h_{w}+\frac{d}{2}-\sqrt{h_{w}^{2}+h_{w} d}\right)
\end{array}\right\},
\end{aligned}
$$

where $Q_{F}$ is the seepage volume of the excavation surface stratum within a certain period of time, $\mathrm{m}^{3}$.

4.2.4. Calculation Results of Water Seepage. According to the specific stratum permeability coefficient, excavation speed, groundwater head, and chamber soil height, the seepage volume of the tunnel excavation face and shield surrounding the stratum to the chamber can be obtained, and the variation of the water content of the chamber soil during the seepage process can then be calculated according to the excavation soil volume of each ring and the initial water content of the chamber soil.

Based on the above measured water seepage from the excavation surface and the surrounding stratum of the shield to the chamber, the calculated value of the model was compared with the measured value, as shown in Figure 10. Here, it can be seen that the established seepage calculation model has good accuracy. Because the shield at the selected section was in a downhill state, more water might flow to the chamber under the action of gravity; however, the influence of the shield angle was not considered in the calculation model, and thus the measured value will be slightly larger than the calculated value. Through the field test, it was observed that a large amount of groundwater in the chamber comes from the gap between the shield cylinder and the stratum. In the construction, the water stop hoops between the segments and the stratum were provided every 5 rings, which can effectively limit the seepage caused by no solidification of grouting behind the segments. However, the impermeability of the newly injected grouting is poor when it is not solidified, so it is indeed possible to have a small amount of seepage. But when establishing the calculation model, it was assumed that there will be no water seepage behind the shield tail due to the existence of grouting. The length of the water seepage path along the direction of the shield cylinder was taken as the length of the cylinder, and the consistency between the calculation results and the measured results is good. Therefore, it is considered that the water seepage near the newly assembled segments can be ignored, and the groundwater seepage along the shield cylinder ends at the shield tail. Overall, the calculation model of seepage can accurately reflect the actual situation.

\subsection{Influence Law and Sensitivity Analysis of Each Parameter} on Moisture Content of Chamber Soil. The high water content of the chamber soil is one of the characteristics of the phenomenon of chamber soil sliming. To clarify the influence rule and occurrence condition of the relevant factors of this phenomenon, the water seepage volume was converted into the water content of the chamber soil for further analysis. The water head in the chamber, excavation time, permeability coefficient, and groundwater head are important factors affecting the water content of the chamber soil, and the value range of each parameter is listed in Table 3. The EPB tunneling mode is an ideal construction mode; that is, the chamber pressure is balanced with the earth-water pressure of the excavation face, and the water in the stratum will not seep into the chamber, and thus the EPB mode was not considered in this study. When the chamber was in semiopen under-pressure mode, the water pressure in the chamber was calculated separately. The height of the water level in the chamber was the same as the height of the chamber soil.

The influence rules of the water head in the chamber, the excavation time, the permeability coefficient, and the groundwater head on the moisture content of the discharged soil are shown in Figures 11-14, respectively. Figure 11 shows that the water head in the chamber is negatively correlated with the moisture content of the discharged soil. Increasing the height of the chamber soil was conducive to reducing the seepage of groundwater into the pressure chamber. It can be seen from Figure 12 that when $k=10^{-5} \mathrm{~m} / \mathrm{s}$ and $\alpha=2 / 3$, the moisture content of the discharged soil increased significantly with an increase in the excavation time. Figure 13 shows that the moisture content curve of the discharged soil turned when the permeability coefficient, $k$, was $10^{-6} \mathrm{~m} / \mathrm{s}$; when $k$ increased from $10^{-7}$ to $10^{-6} \mathrm{~m} / \mathrm{s}$, the discharged soil moisture content increased slowly, whereas when $k$ increased from $10^{-6}$ to $10^{-5} \mathrm{~m} / \mathrm{s}$, the discharged soil moisture content increased rapidly. As shown in Figure 14, with an increase in the groundwater head, the moisture content of the discharged soil slightly increased, and, with a decrease of the water head coefficient in the chamber, the influence of the groundwater head on the moisture content of the discharged soil decreased.

To propose effective prevention and control measures against the phenomenon of chamber soil sliming, the key factors affecting this phenomenon must first be clarified. Therefore, a sensitivity analysis method was used to analyze the correlation between the relevant parameters and the moisture content of the discharged soil. Meanwhile, through a sensitivity analysis, the main and secondary influence parameters of chamber soil sliming can be determined, 


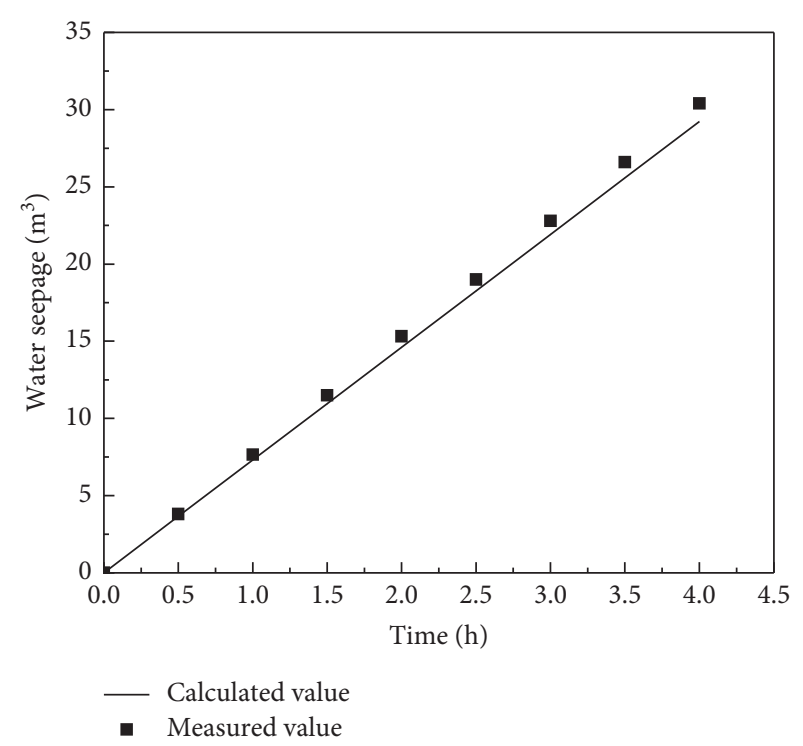

Figure 10: Measured and calculated values of the water seepage volume.

TABLE 3: Seepage model parameters.

\begin{tabular}{lccc}
\hline$\alpha$ & $t$ (h/ring) & $k(\mathrm{~m} / \mathrm{s})$ & $h_{w}(\mathrm{~m})$ \\
\hline $2 / 3,1 / 2,1 / 3$ & $4,6,8$ & $10^{-5}, 10^{-6}, 10^{-7}$ & $7,10,13,16$ \\
\hline
\end{tabular}

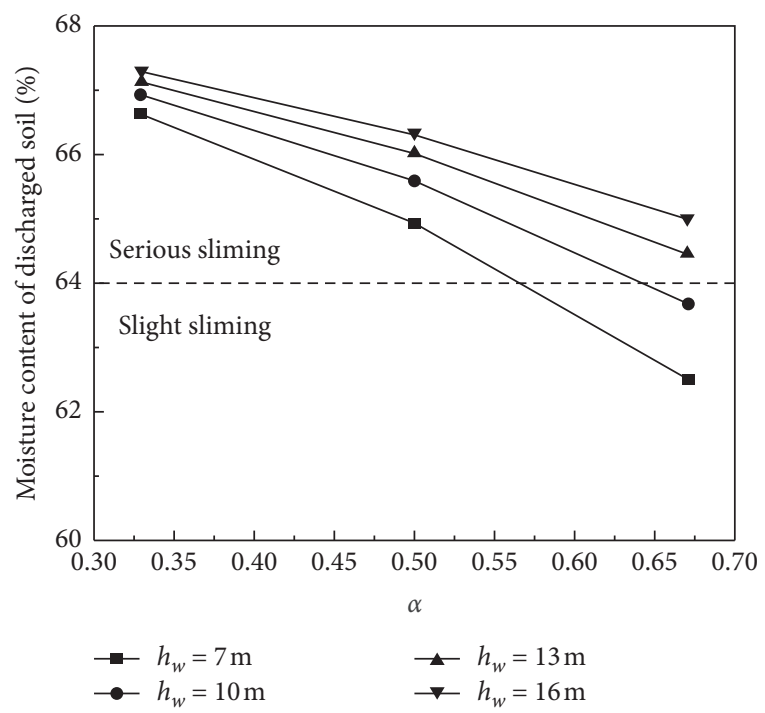

FIGURE 11: Influence of $\alpha$ on the moisture content of chamber soil when $k=10^{-5} \mathrm{~m} / \mathrm{s}$ and $t=4 \mathrm{~h} / \mathrm{ring}$.

which is helpful when proposing control measures. The first step of the sensitivity analysis method was to establish an analysis system model [29], that is, the functional relationship between the system characteristic $P$ and factors $x_{1}, x_{2}, \ldots, x_{n}$; for example, $P=f\left(x_{1}, x_{2}, \ldots, x_{n}\right)$. The second step was to provide the benchmark parameter set according to the specific problems to be analyzed. The benchmark value and range of variation of each parameter

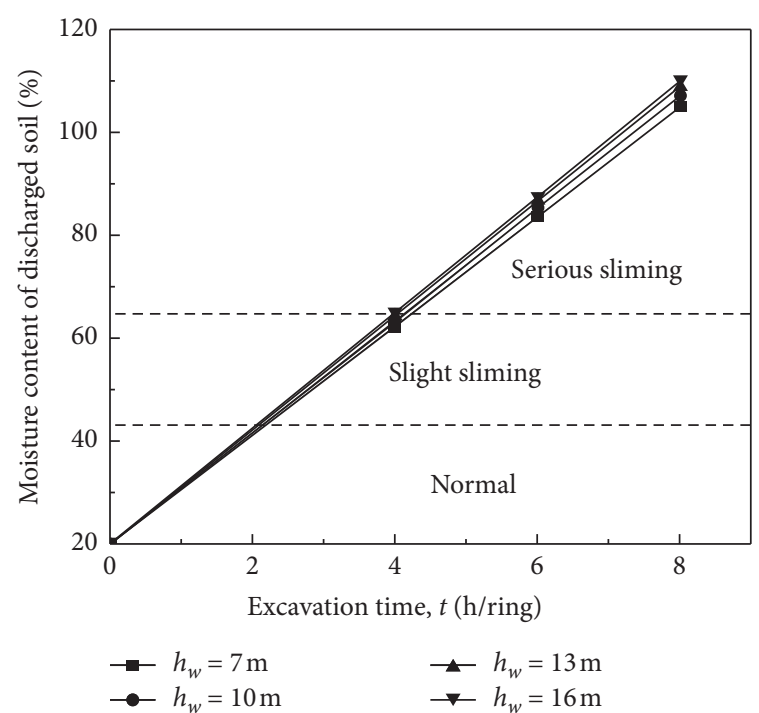

FIGURE 12: Influence of $t$ on the moisture content of chamber soil when $k=10^{-5} \mathrm{~m} / \mathrm{s}$ and $\alpha=2 / 3$.

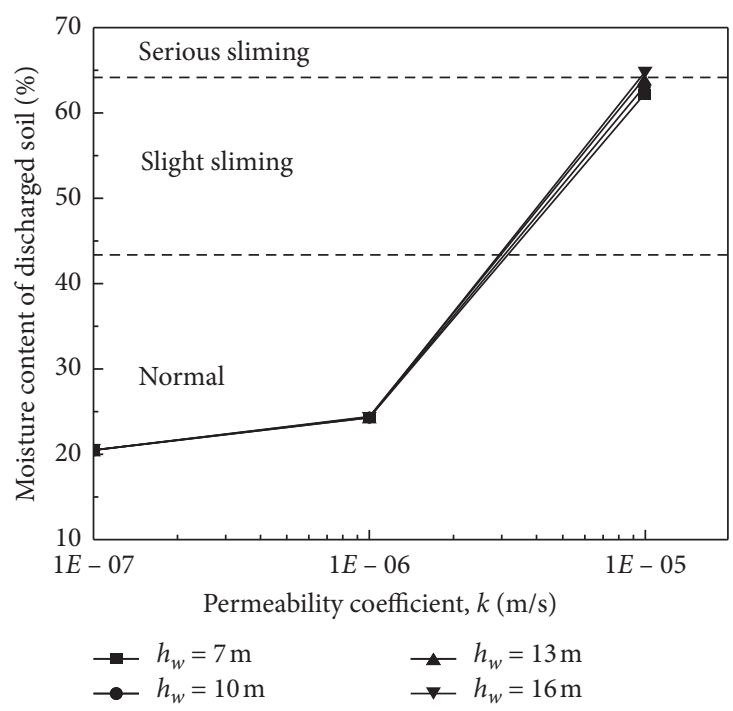

FIGURE 13: Influence of $k$ on the moisture content of chamber soil when $t=4 \mathrm{~h} /$ ring and $\alpha=2 / 3$.

selected in this study are listed in Table 4, and the sensitivity of each parameter was then calculated according to the following equation:

$$
S_{k}=\frac{|\Delta P / P|}{\left|\Delta X_{k} / X_{k}\right|}=\left|\frac{\Delta P}{\Delta X_{k}}\right|\left|\frac{X_{k}}{P}\right|,
$$

where $S_{k}$ is the sensitivity of factor $x_{k}$, where $k=1,2, \ldots, n$; $|\Delta P / P|$ is the relative change rate of the system characteristics; and $\left|\Delta X_{k} / X_{k}\right|$ is the relative change rate of a certain factor.

Only one factor is changed in each calculation, and other factors remain unchanged. The sensitivity of each factor is analyzed individually, the results of which are listed in 


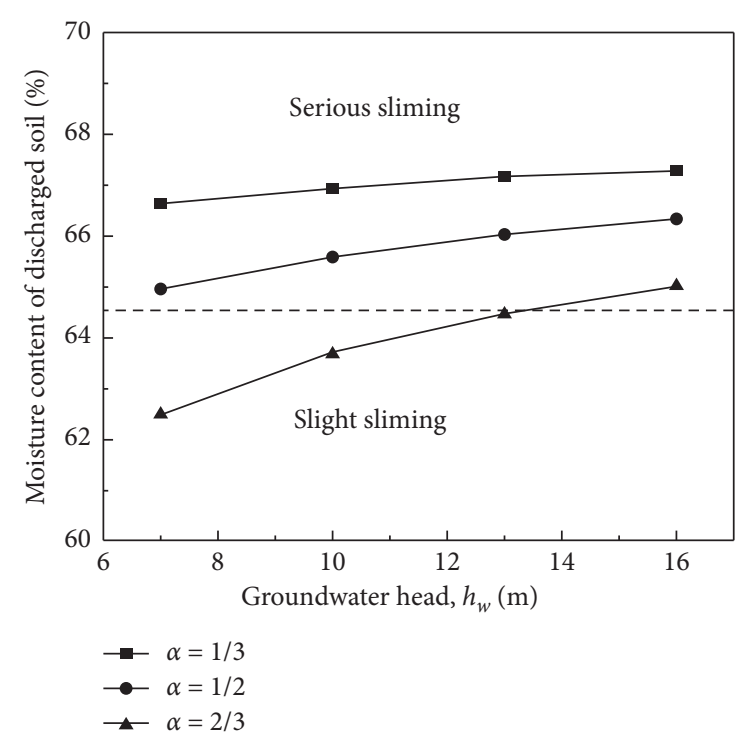

FIGURE 14: Influence of $h_{w}$ on the moisture content of chamber soil when $t=4 \mathrm{~h} /$ ring and $k=10^{-5} \mathrm{~m} / \mathrm{s}$.

TABLE 4: Reference value and change range of each parameter.

\begin{tabular}{lcccc}
\hline Parameter & $h_{w}(\mathrm{~m})$ & $\mathrm{A}$ & $t(\mathrm{~h} / \mathrm{ring})$ & $k(\mathrm{~m} / \mathrm{s})$ \\
\hline Benchmark value & 16 & $1 / 2$ & 4 & $10^{-5}$ \\
Variation range & $7 \sim 16$ & $1 / 3 \sim 2 / 3$ & $4 \sim 8$ & $10^{-7} \sim 10^{-5}$ \\
\hline
\end{tabular}

Table 5. Here, it can be seen that, among the four selected parameters, the moisture content of the discharged soil has the highest sensitivity to the excavating time, $t$, followed by the permeability coefficient, $k$, and water head coefficient in the chamber, $\alpha$; and the relationship between the moisture content of the discharged soil and groundwater head, $h_{w}$, was the furthest. Therefore, in the process of construction, the most effective measure used to control the phenomenon of chamber soil sliming is to shorten the excavation time and reduce the permeability coefficient of the chamber soil by means of soil conditioning.

4.4. Occurrence Conditions and Critical Values. Combined with the above research and engineering measured data, the possibility of chamber soil sliming under semiopen underpressure mode was evaluated based on the permeability coefficient; the pressure difference between the excavation surface water pressure and chamber pressure, $P$; and the excavation time. After the weathered diorite was excavated, the liquid limit of the discharged soil, $w_{L}$, was approximately $21.5 \%$. Combined with the moisture content of the discharged soil on site, it was considered that when the moisture content of the chamber soil, $w$, is $2 w_{L} \leq w \leq 3 w_{L}$, slight chamber soil sliming may occur, whereas when $w \geq 3 w_{L}$, serious chamber soil sliming may occur. Thus, the critical condition for the occurrence of chamber soil sliming is as shown in Figure 15.

According to the established model, when the excavation time was $4 \mathrm{~h} /$ ring and the permeability coefficient was
TABLE 5: Sensitivity of moisture content of discharged soil to each parameter.

\begin{tabular}{lcccc}
\hline Parameter & $h_{w}(\mathrm{~m})$ & $\alpha$ & $t(\mathrm{~h} / \mathrm{ring})$ & $k(\mathrm{~m} / \mathrm{s})$ \\
\hline Sensitivity & 0.056 & 0.113 & 0.769 & 0.692 \\
\hline
\end{tabular}

$k \geq 5 \times 10^{-6} \mathrm{~m} / \mathrm{s}$, chamber soil sliming may occur, and when $k \geq 1 \times 10^{-5} \mathrm{~m} / \mathrm{s}$, this phenomenon is more serious. The longer the excavation time, the lower the permeability coefficient required for sliming to occur. When the advancing time was $6 \mathrm{~h} /$ ring and $k \geq 4 \times 10^{-6} \mathrm{~m} / \mathrm{s}$, chamber soil sliming will occur, and when $k \geq 7 \times 10^{-6} \mathrm{~m} / \mathrm{s}$, more serious sliming may occur. Therefore, with an increase in the advancing time, the range of formation permeability coefficient, which may cause serious chamber soil sliming, clearly increases.

\section{Discussion}

5.1. Comparison of the Critical Conditions of Sliming and Spewing of Chamber Soil. The difference and connection between the sliming and spewing of the chamber soil are described above. The sliming of the chamber soil was excavated under the condition of a nonfull chamber and low chamber pressure and a large amount of groundwater seepage into the chamber, resulting in a thin mud state of chamber soil close to the liquid phase. Under the condition of tunneling with a full chamber and high chamber pressure, there was a large pressure difference between the water pressure in the chamber and the atmospheric pressure at the screw conveyor outlet, which results in a spewing of a mixture of soil and water in the chamber. In both cases, the moisture content of the discharged soil was higher; thus, it was easily confused during the construction process. However, the moisture content of the discharge soil during sliming was generally higher than that during the spewing.

The critical conditions of the spewing phenomenon have been studied by scholars $[10,11]$. Zheng et al. considered the water pressure of the screw conveyor outlet and groundwater flow as the spewing conditions and calculated the range of the groundwater pressure at the center of the excavation surface and the permeability coefficient of the chamber soil when the spewing occurred [10]. The groundwater head and permeability coefficient of the project were introduced under the critical condition of spewing by Zheng et al. [10] who concluded that serious gushing will occur. However, based on the observation of the discharge of soil during the site construction, it was found that the soil was not spewed from the outlet. As the reason for this difference, the excavation surface strength of the project was high, the semiopen under-pressure mode was adopted by the construction personnel, and the chamber pressure was relatively low.

As shown in Figure 15, the stratum permeability coefficient and the pressure difference between the excavation surface water pressure and the chamber pressure were used to analyze the critical conditions for the occurrence of chamber soil sliming under different excavation speeds. Compared with the above critical conditions of spewing, the 


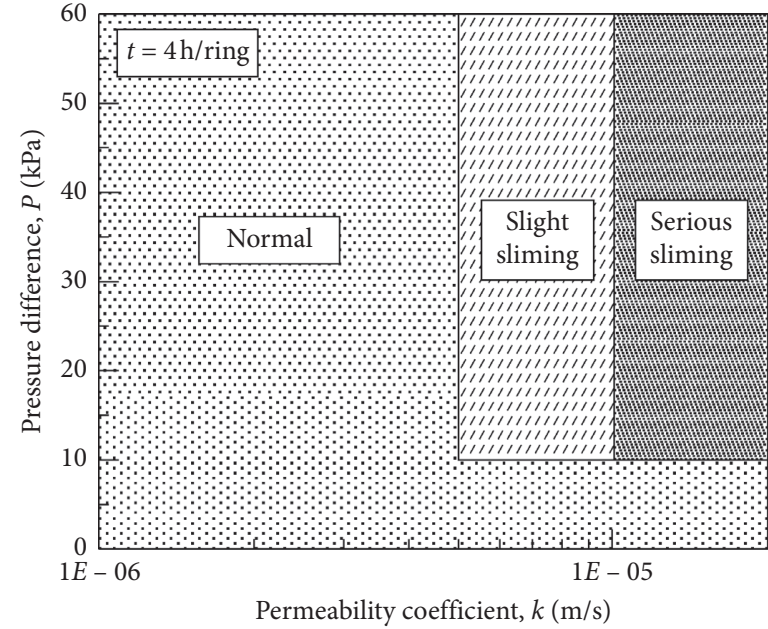

(a)

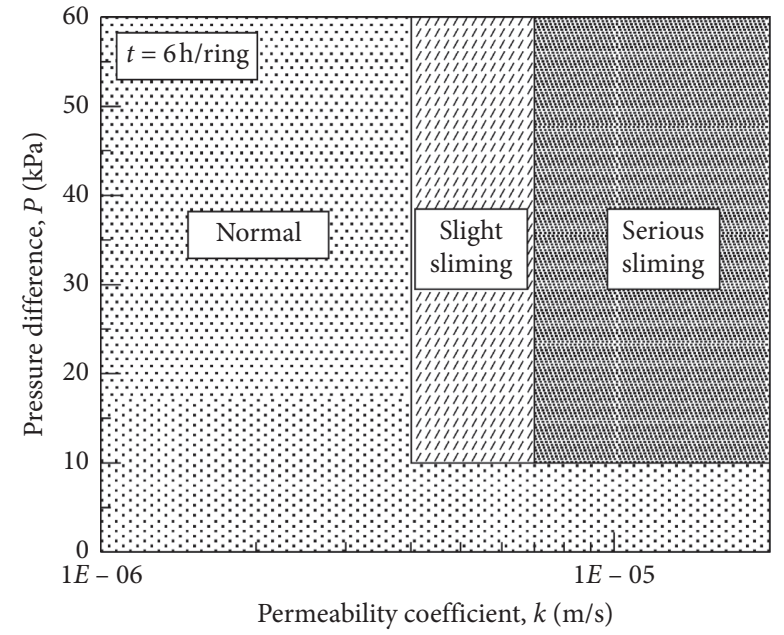

(b)

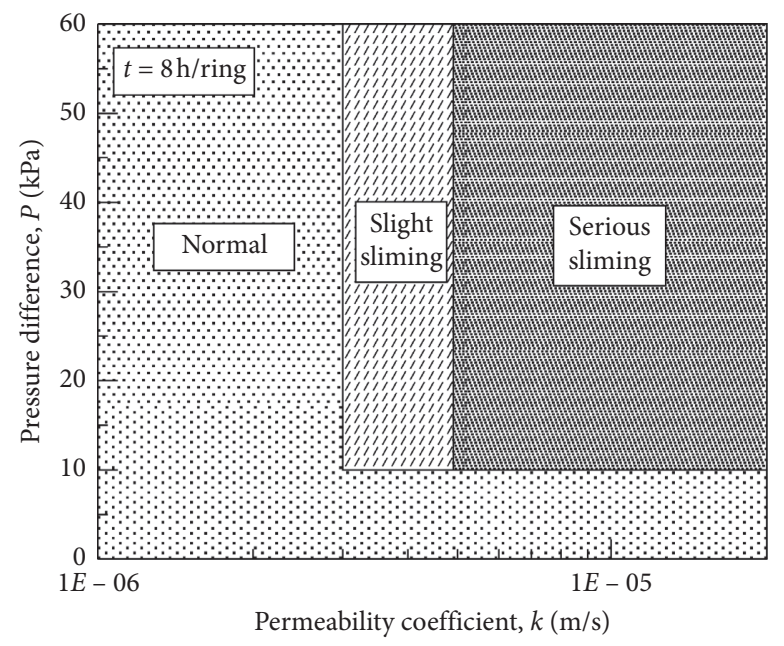

(c)

Figure 15: Critical condition of the sliming phenomenon of chamber soil.

influence of the construction time was also considered. Taking this project as an example, the permeability coefficient of the stratum was approximately $1 \times 10^{-5} \mathrm{~m} / \mathrm{s}$, semiopen under-pressure mode was used for driving, and no soil conditioning additive was used to improve the plastic flow of the chamber soil. The project passed through completely weathered diorite or strongly weathered diorite strata in the full section in the first 330 rings. It can be seen from Figure 4 that the excavation speed was relatively fast, namely, approximately $0.8 \mathrm{~h}$ for each ring, without the occurrence of chamber soil sliming. However, at the 340-350th rings, the invasion of the moderately weathered diorite with high strength resulted in a time of approximately $10 \mathrm{~h}$ for each ring excavation. It can be seen from Figure 5 that the difference between the excavation surface water pressure and chamber pressure in the actual project was approximately $50-60 \mathrm{kPa}$. Therefore, according to the critical conditions in Figure 15, serious soil sliming probably occurred in the 340-350th rings, indicating that the moisture content of discharged soil is $w \geq 3 w_{L}$, whereas the measured water content of the discharged soil on site is $2.6-2.8 w_{L}$, which shows some errors. This analysis result might be due to the fact that the water separated from the discharged soil inevitably causes part of the water to be lost from the soil sample when the soil sample is taken from the discharge outlet and the discharged soil pit, which results in the measured water content of the soil being less than the calculated value. In addition, the calculation model simplifies the seepage process of groundwater, which also leads to a difference between the calculated and measured values.

To summarize, the critical condition indexes of the chamber soil sliming and spewing are similar, with both considering the groundwater pressure and the permeability coefficient of the stratum, and the results are close to those of the actual project. It is easy to confuse the phenomena of sliming and spewing of the chamber soil. When judging whether these two phenomena will occur, the shield machine driving mode, stratum parameters, chamber pressure, 
groundwater pressure, and excavation time should be comprehensively considered.

5.2. Prevention Measures of Chamber Soil Sliming. According to the results in Figures 11-14 and Table 5, the most effective measure used to avoid chamber soil sliming is to control the excavation time and the permeability coefficient of the chamber soil during the construction.

Combined with the above research, a semiopen underpressure mode is most suitable for stratum with high strength and low water amount. When excavating in weathered stratum with a large amount of water, a large permeability coefficient, and high strength, this mode can also be used to reduce the thrust and the wear of the cutter head and improve the construction speed. Here, the excavation time should be strictly controlled to avoid the phenomenon of sliming caused by excessive groundwater seepage into the pressure chamber. Taking the project as an example, the stratum permeability coefficient was $1 \times 10^{-5} \mathrm{~m} / \mathrm{s}$, and the groundwater head was $7-16 \mathrm{~m}$; if no conditioning measures are taken for the soil in the chamber, the chamber soil volume should be controlled to account for at least $2 / 3$ of the chamber volume, and the excavation time should not exceed $2 \mathrm{~h} / \mathrm{ring}$.

The shield machine used in the project was a four-spoke panel composite EPB shield, the cutting capacity of which was significantly reduced when encountering moderately weathered diorite; in addition, the speed was limited, which resulted in a large amount of groundwater seepage into the pressure chamber, and the soil in the chamber could not be smoothly discharged. A large amount of thin mud-like chamber soil leaked into the bottom of the tunnel, which affected the working environment and segment assembly. It took a long time for the construction personnel to clean up the soil with a high moisture content, which further limited the construction speed. More groundwater then seeped into the chamber, creating a vicious cycle. Thus, when the speed cannot be increased, a low chamber soil height should be avoided. According to this study, the chamber soil height should be kept at $2 / 3$ or more of the pressure chamber height, and the soil conditioning measures should be taken so the chamber soil forms a plastic flow state, with a permeability coefficient of less than $1 \times 10^{-6} \mathrm{~m} / \mathrm{s}$ to balance the groundwater and Earth pressure on the excavation surface and prevent the groundwater seepage into the pressure chamber. In the case of a dense formation and good airproof capability, the method of applying air pressure to the upper half of the pressure chamber can also be adopted simultaneously. Maintaining an air pressure slightly higher than the groundwater pressure in the upper half of the chamber can prevent a large amount of groundwater seepage. In addition, through an observation of the situation occurring in the chamber, it was found that the stratum around the shield and the excavation surface will seep into the chamber, and the seeping water mainly comes from the stratum around the shield. Therefore, during the process of shield machine propulsion, measures can be taken to inject waterproof materials into the gap between the shield body and stratum, such as bentonite slurry with a high density and viscosity, reducing the water seepage around the shield.

\section{Conclusions}

(1) Chamber soil sliming is a phenomenon in which chamber soil is in a thin mud state, with no pressure balance in the pressure chamber of the EPB shield and an excessive water content of the chamber soil owing to the continuous seepage of groundwater into the chamber; in addition, the chamber pressure is relatively low, which is different from the phenomenon of spewing when the chamber pressure is relatively high.

(2) Based on the field measurement, a large amount of water seepage from the stratum around the tunnel excavation surface and shield to the chamber is a significant factor leading to chamber soil sliming during the construction process. Considering the influence of the water head in the chamber, the excavation time, the permeability coefficient of the stratum, and the groundwater head, a calculation model of water seepage was established, which can be used to calculate the change law of the water seepage volume and the moisture content of the chamber soil. The field-measured and calculated values of the water seepage were verified, and it is considered that the calculation model of the water seepage conforms relatively well to actual engineering practice.

(3) The influence of each parameter on the moisture content of the chamber soil and the sensitivity between each parameter and the phenomenon of chamber soil sliming were analyzed. On this basis, the critical conditions for the occurrence of sliming were divided, and the relations and differences between the critical conditions of sliming and the spewing phenomena were discussed.

(4) Regarding the phenomenon of chamber soil sliming, several preventative measures were proposed. When the EPB shield is used for tunneling in water-rich weathered rock stratum with high permeability and high strength, semiopen under-pressure excavating mode can be used. However, to avoid excessive water seepage in the chamber, control of the excavation time is recommended to be within $2 \mathrm{~h} / \mathrm{ring}$. When the speed cannot be increased for some objective reasons, the chamber soil height should be kept at $2 / 3$ or more of the pressure chamber height, and soil conditioning measures should be taken such that the soil forms a plastic flow. In addition, the application of air pressure to the upper part of the chamber without soil, or the injection of a thick slurry and other waterproof materials into the gap between the shield shell and the stratum during the excavation, can be considered to prevent the occurrence of sliming. 


\section{Data Availability}

The data used to support the findings of this study are available from the corresponding author upon request.

\section{Conflicts of Interest}

The authors declare that they have no conflicts of interest.

\section{Acknowledgments}

This research was supported by the National Program on Key Basic Research Project of China (973 Program) (2015CB057803).

\section{References}

[1] R. K. Goel, J. L. Jethwa, and A. G. Paithankar, “Tunnelling through the young Himalayas - a case history of the ManeriUttarkashi power tunnel," Engineering Geology, vol. 39, no. 12, pp. 31-44, 1995.

[2] G.-H. Zhang, Y.-Y. Jiao, and H. Wang, "Outstanding issues in excavation of deep and long rock tunnels: a case study," Canadian Geotechnical Journal, vol. 51, no. 9, pp. 984-994, 2014.

[3] G.-H. Zhang, Y.-Y. Jiao, C.-X. Ma, H. Wang, L.-B. Chen, and Z.-C. Tang, "Alteration characteristics of granite contact zone and treatment measures for inrush hazards during tunnel construction-a case study," Engineering Geology, vol. 235, no. 9, pp. 64-80, 2018.

[4] S. S. Lv, W. Liu, S. H. Zhai, and P. S. Chen, "Influence of water inrush from excavation surface on the stress and deformation of tunnel-forming structure at the launching-arrival stage of subway shield," Advances in Civil Engineering, vol. 2019, Article ID 6989730, 20 pages, 2019.

[5] W. C. Cheng, G. Li, A. Zhou, and J. Xu, "Rethinking the water leak incident of tunnel Luo09 to prepare for a challenging future," Advances in Civil Engineering, vol. 2019, Article ID 4695987, 11 pages, 2019.

[6] N. Bilgin and M. Algan, "The performance of a TBM in a squeezing ground at Uluabat, Turkey," Tunnelling and Underground Space Technology, vol. 32, pp. 58-65, 2012.

[7] E. Avunduk and H. Copur, "Empirical modeling for predicting excavation performance of EPB TBM based on soil properties," Tunnelling and Underground Space Technology, vol. 71, pp. 340-353, 2018.

[8] K. Bäppler and W. Burger, "Innovation track of multi-mode machines for complex ground conditions," in Proceedings of the Swiss Tunnel Congress, pp. 122-129, San Francisco, CA, USA, April 2016.

[9] C. Budach and M. Thewes, "Application ranges of EPB shields in coarse ground based on laboratory research," Tunnelling and Underground Space Technology, vol. 50, pp. 296-304, 2015.

[10] G. Zheng, X. Dai, and Y. Diao, "Parameter analysis of water flow during EPBS tunnelling and an evaluation method of spewing failure based on a simplified model," Engineering Failure Analysis, vol. 58, pp. 96-112, 2015.

[11] W. Zhu, J. S. Qin, and K. L. Wei, "Research on the mechanism of the spewing in the EPB shield tunneling," Chinese Journal of Geotechnical Engineering, vol. 26, no. 5, pp. 589-593, 2004.

[12] N. Zhang, J. S. Shen, A. Zhou, and A. Arulrajah, "Tunneling induced geohazards in mylonitic rock faults with rich groundwater: a case study in Guangzhou," Tunnelling and Underground Space Technology, vol. 74, pp. 262-272, 2018.

[13] S. M. Wang, X. X. Lu, X. M. Wang et al., "Soil improvement of EPBS construction in high water pressure and high permeability sand stratum," Advances in Civil Engineering, vol. 2019, Article ID 4503219, 9 pages, 2019.

[14] X. Y. Ye, S. Y. Wang, J. S. Yang, D. C. Sheng, and C. Xiao, "Soil conditioning for EPB shield tunneling in argillaceous siltstone with high content of clay minerals: case study," International Journal of Geomechanics, vol. 17, no. 4, Article ID 05016002, 2016.

[15] P. Liu, S. Wang, L. Ge, M. Thewes, J. Yang, and Y. Xia, "Changes of Atterberg limits and electrochemical behaviors of clays with dispersants as conditioning agents for EPB shield tunnelling," Tunnelling and Underground Space Technology, vol. 73, pp. 244-251, 2018.

[16] D. G. G. de Oliveira, M. Thewes, and M. S. Diederichs, "Clogging and flow assessment of cohesive soils for EPB tunnelling: proposed laboratory tests for soil characterization," Tunnelling and Underground Space Technology, vol. 94, Article ID 103110, 2019.

[17] H. H. Zhu, C. Panpan, Z. Xiaoying, L. Yuanhai, and L. Peinan, "Assessment and structural improvement on the performance of soil chamber system of EPB shield assisted with DEM modeling," Tunnelling and Underground Space Technology, vol. 96, Article ID 103092, 2020.

[18] G. Carrieri, E. Fornari, V. Guglielmetti, and R. Crova, "Torino metro line 1: use of three TBM-EPBs in very coarse grained soil conditions," Tunnelling and Underground Space Technology, vol. 21, no. 3-4, pp. 274-275, 2006.

[19] H. Jiang, Y. S. Jiang, M. L. Huang, and X. Nie, "Study on soil conditioning and key construction parameters of EPB TBM advancing in sand-pebble layer of Beijing metro," Applied Mechanics and Materials, vol. 90-93, pp. 2138-2142, 2011.

[20] F. Ye, Z. Chen, C. H. Sun et al., "Penetration diffusion model for backfill grouting through segments of shield tunnel considering weight of grout," Chinese Journal of Geotechnical Engineering, vol. 38, no. 12, pp. 2175-2183, 2016.

[21] J. N. Shirlaw, "Pressurised TBM tunnelling in mixed face conditions resulting from tropical weathering of igneous rock," Tunnelling and Underground Space Technology, vol. 57, pp. 225-240, 2016.

[22] Anon, GEO Report 298 Ground Control for EPB TBM Tunnelling, Prepared by the Geotechnical Engineering Office, Hong Kong, China, 2014.

[23] H. Basarir, "Engineering geological studies and tunnel support design at Sulakyurt dam site, Turkey," Engineering Geology, vol. 86, no. 4, pp. 225-237, 2006.

[24] S. Dalgic, "Tunneling in squeezing rock, the Bolu tunnel, Anatolian motorway, Turkey," Engineering Geology, vol. 67, no. 1-2, pp. 73-96, 2002.

[25] D. Peila, "Soil conditioning for EPB shield tunnelling," KSCE Journal of Civil Engineering, vol. 18, no. 3, pp. 831-836, 2014.

[26] Z. P. Zhu, Study on Anti-blowout Induced by EPB Shield Tunneling under High Water Pressure in Sandy Cobble Stratum, Beijing Jiaotong University, Beijing, China, 2016, in Chinese.

[27] X. Li, L. Wang, M. Hao, Y. Zhong, and B. Zhang, "An analytical solution for the radial flow of variable density grout in rock fractures," Construction and Building Materials, vol. 206, pp. 630-640, 2019.

[28] X. L. Liu, F. Wang, J. Huang et al., "Grout diffusion in silty fine sand stratum with high groundwater level for tunnel 
construction," Tunnelling and Underground Space Technology, vol. 93, Article ID 103051, 2019.

[29] G. Zhang and W. S. Zhu, "Parameter sensitivity analysis and test scheme optimization," Rock and Soil Mechanics, vol. 14, no. 1, pp. 53-60, 1993, in Chinese. 